\title{
USO DE FLUORESCÊNCIA DE CLOROFILA PARA AVALIAR A QUALIDADE FISIOLÓGICA DE SEMENTES DE CENOURA
}

\author{
CLEITON STIGGER PERLEBERG \\ Engenheiro Agrônomo
}

Orientador: Prof. Dr. SILVIO MOURE CICERO

Tese apresentada à Escola Superior de Agricultura "Luiz de Queiroz", Universidade de São Paulo, para obtenção do título de Doutor em Agronomia, Área de Concentração: Fitotecnia.

\section{PIRACICABA}

Estado de São Paulo - Brasil

Maio - 2001 


\title{
Dados Internacionais de Catalogação na Publicação (CIP) DIVISÃO DE BIBLIOTECA E DOCUMENTAÇÃO - Campus "Luiz de Queiroz"/USP
}

\author{
Perteberg, Cleiton Stigger \\ Uso de fluorescência de clorofila para avaliar a qualidade fisiológica de sementes de \\ cenoura / Cleiton Stigger Penleberg. - - Piracicaba, 2001. \\ $37 \mathrm{p}$. \\ Tese (doutorado) - Escola Superior de Agricultura Luiz de Queiroz, 2001. \\ Bibliografia. \\ 1. Clorofila 2. Envelhecimento precoce 3. Inflorescência 4. Maturidade 5. Qualidade \\ fisiológica 6. Semente de cenoura 7. Teste de tetrazólio 8 . Vigor da semente I. Tímulo
}

$\operatorname{CDD} 635.13$ 


$$
\begin{gathered}
\text { "Tudo tem seu tempo, } \\
\text { há um momento oportuno } \\
\text { para cada empreendimento debaixo do céu. } \\
\text { Tempo de nascer, e tempo de morrer; } \\
\text { tempo de plantar, e tempo de colher a planta. } \\
\text { Tempo de chorar, e tempo de rir; } \\
\text { tempo de gemer, e tempo de dançar. } \\
\text { Tempo de amar, e tempo de odiar, } \\
\text { tempo de guerra, e tempo de paz." }
\end{gathered}
$$

"Etiene, meu amor, tu soubestes rir comigo nos momentos de alegria e chorar nos momentos de dor; me acompanhar nas viagens e também aguardar minha volta suportando a saudade; me dar força para lutar pelos nossos ideais; me compreender nos momentos de atribulação e, sobretudo, me amar e me ensinar a te amar.

Antônio, meu filho, não pude estar sempre ao teu lado, mas certamente o teu existir me deu forças para continuar; no momento em que nascestes e te tomei em meus braços meu ser inundou-se do mais puro amor."

À minha esposa Etiene de Azevedo Perleberg e à meu filho Antônio de Azevedo Perleberg, razões do meu existir, DEDICO ! 


\section{AGRADECIMENTOS}

Ao Prof. Silvio Moure Cicero pela orientação, paciência e amizade durante a realização deste trabalho.

A Gerie van der Heijden, Henk Jalink, Gerrit Polder, Rob van der Schoor e Jaap van Pijlen pela orientação na condução do trabalho junto ao "Plant Research Intemational" (PRI - Wageningen/Holanda).

Aos Professores Julio Marcos Filho e Walter Rodrigues da Silva e a Dra. Ana Dionísia da Luz Coelho Novembre, do Departamento de Produção Vegetal da ESALQ-USP, pelos ensinamentos.

Aos Professores Francisco Amaral Villela e Maria Ângela André Tillmann, da Faculdade de Agronomia "Eliseu Maciel" (UFPEL - Pelotas), pelo exemplo e incentivo.

Aos amigos Angelica Brod Rodo, Geni Carmen Zanol, Osmar Paulo Beckert, Salvador Barros Torres e Silvana Ohse, que acreditaram que este trabalho seria possível.

Aos colegas de curso, pela amizade, convivência e auxílio.

Às funcionárias do Departamento de Fitotecnia Ilze Helena de Gaspari das Neves e Maria Ivete Monteiro de Almeida, meu obrigado. 
Ao CNPq pela concessão das bolsas de Doutorado e Doutorado Sanduíche no Exterior.

Ao Eng ${ }^{\circ}$. Agro. Gilberto Pozzan - HORTEC Sementes Ltda. pelo auxílio na obtenção das sementes utilizadas neste trabalho.

A meu Pai Vilmar Perleberg e minha Mãe Zeni Maria Stigger Perleberg, que incondicionalmente dedicaram sua vida para que eu pudesse me dedicar aos estudos.

E a todos aqueles que distantes, seja por atos ou orações, participaram deste trabalho, minha gratidão. 


\section{SUMÁRIO}

Página

RESUMO

viii

SUMMARY ix

1 INTRODUÇÃO

1

2 REVISÃO DE LITERATURA.........................................................................

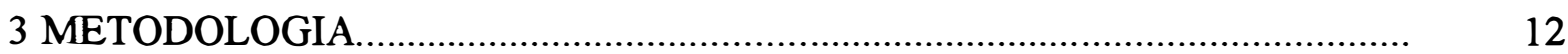

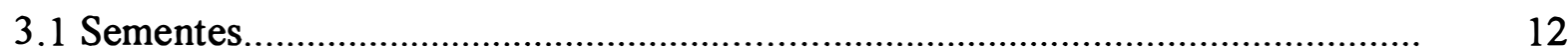

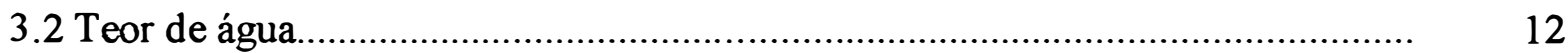

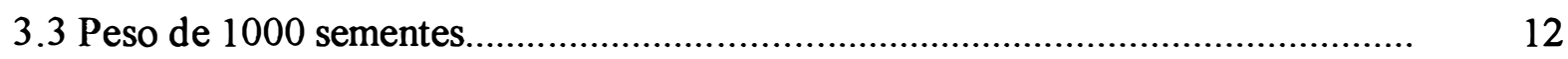

3.4 Medida de fluorescência de clorofila.................................................................... 13

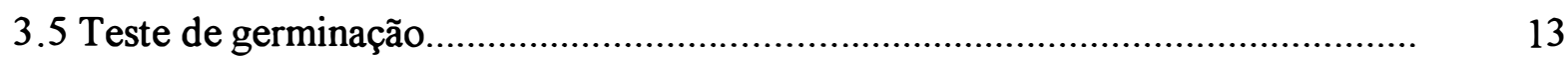

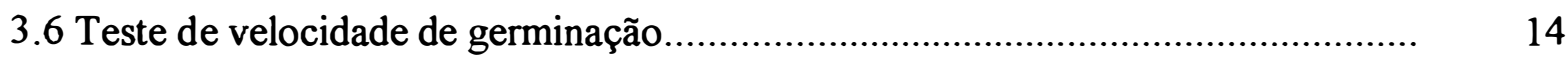

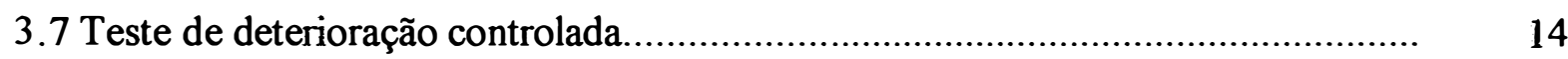

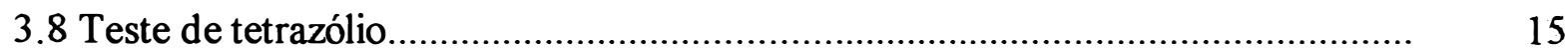

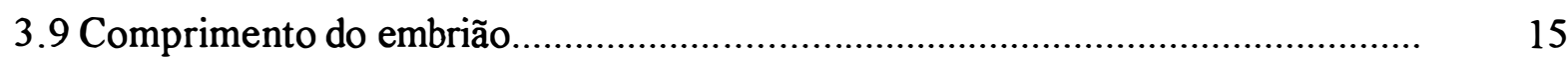

3.10 Delineamento estatístico.............................................................................. 16

4 RESULTADOS E DISCUSSÃO.................................................................... 17

4.1 Teor de água, peso de 1000 sementes e comprimento do embrião....................... 17

4.2 Fluorescência de clorofila.................................................................................... 19

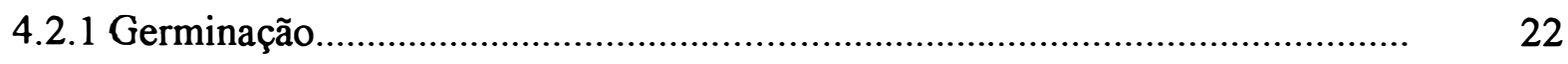

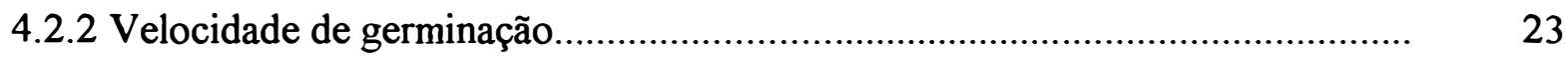

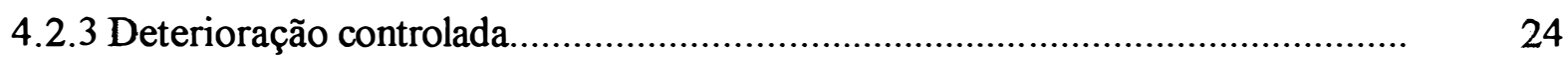

4.3 Teste de Tetrazólio........................................................................................ 26

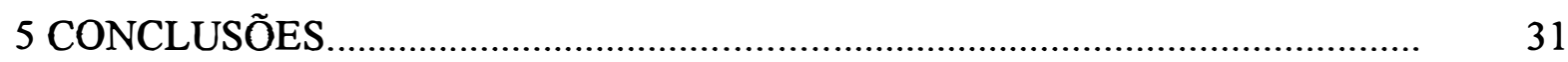

REFERÊNCIAS BIBLIOGRÁFICAS .......................................................... 32 


\section{CURRICULUM VITAE}

Cleiton Stigger Perleberg, nascido a 06 de julho de 1971 em Pelotas/RS, formado em Engenharia Agronômica em 05 de fevereiro de 1994 pela Faculdade de Agronomia "Eliseu Maciel" - Universidade Federal de Pelotas, Mestre em Ciências em 31 de maio de 1996 pela Faculdade de Agronomia "Eliseu Maciel" - Universidade Federal de Pelotas, atualmente exercendo atividades na Divisão de Sementes e Mudas Departamento de Produção Vegetal, Entidade Certificadora e Fiscalizadora, na Secretaria da Agricultura e Abastecimento do Estado do Rio Grande do Sul. 


\title{
USO DE FLUORESCÊNCIA DE CLOROFILA PARA AVALIAR A QUALIDADE FISIOLÓGICA DE SEMENTES DE CENOURA
}

\author{
Autor: CLEITON STIGGER PERLEBERG \\ Orientador: Prof. SILVIO MOURE CICERO
}

\section{RESUMO}

A estrutura floral das plantas de cenoura apresenta maturação desuniforme das umbelas, constituindo um problema para a colheita de sementes. Além disso, a pesquisa tem relatado que a qualidade das sementes é mais dependente do grau de maturidade do embrião do que do tamanho da semente ou da umbela de origem. No presente trabalho, utilizou-se a fluorescência de clorofila das sementes provenientes das umbelas primária, secundária e terciária para determinar a sua qualidade fisiológica (testes de germinação, deterioração controlada e tetrazólio). Três classes de fluorescência de clorofila foram selecionadas, considerando as correspondentes faixas de corrente elétrica captadas: baixa (10-20 pA), média (20-40pA) e alta (> $40 \mathrm{pA})$. Com base nos resultados obtidos concluiu-se que $\mathrm{o}$ uso de fluorescência de clorofila de sementes de cenoura, como método não destrutivo, é viável para determinar a qualidade fisiológica de sementes com diferentes níveis de maturidade. Sementes com teor de fluorescência de clorofila entre 10-20 pA, independentemente da umbela de origem, apresentam maiores valores de germinação e de vigor, em relação àquelas com fluorescência de clorofila mais elevado (acima de 20 $\mathrm{pA})$. 


\title{
USING CHLOROPHYLL FLUORESCENCE TO EVALUATE THE PHYSIOLOGICAL QUALITY OF CARROT SEEDS
}

\author{
Author: CLEITON STIGGER PERLEBERG \\ Adviser: Prof. SILVIO MOURE CÍCERO
}

SUMMARY

The floral structure of the carrot plants, with no uniform maturation of the umbels it is a problem to the seed harvest. Some researchers, however, have been considering that seed quality is more dependent on the embryos maturity degree than on the umbel of origin or the seed size. In the present work, the method of chlorophyll fluorescence was used to determine the physiological quality (germination, controlled deterioration and tetrazolium tests) of the seeds from the primary, secondary and tertiary umbels. Three levels of chlorophyll fluorescence were determined, according the corresponding electrical signal: low (10-20 pA), medium (20-40 pA) and high $(>40$ $\mathrm{pA}$ ). Based on the results, it was possible to conclude that the use of the chlorophyll fluorescence of carrot seeds is a viable non-destructive method to determine the physiological quality of the seeds with different levels of maturity. Seeds with low chlorophyll fluorescence, between 10-20 pA, independently of the umbel of origin, presented larger germination and vigour values, compared to those with higher chlorophyll fluorescence $(>20 \mathrm{pA})$. 


\section{INTRODUÇÃO}

A cultura da cenoura, de grande valor econômico e alimentar, ocupa lugar de destaque no meio olerícola, figurando entre as cinco espécies de maior importância econômica no Brasil.

Grande parte do sucesso da implantação deste cultivo depende da qualidade das sementes empregadas; o termo qualidade, aplicado às sementes, resume o somatório de todos os atributos genéticos, fisicos, fisiológicos e sanitários que afetam a sua capacidade de originar plântulas normais (Popinigis, 1985), sendo esta qualidade, em grande parte, determinada ainda no campo, durante a fase de produção.

A produção de sementes de cenoura tem crescido significativamente nos últimos anos; em 1983, o país dependia quase que exclusivamente da importação destas sementes, tendo hoje substituído esta total dependência por uma representativa produção nacional.

Existem dois sistemas de produção de sementes de cenoura: sementesemente e raiz-semente. No Brasil, em escala comercial, predomina o sistema sementesemente; entretanto, os produtores que produzem sua própria semente ou aqueles que participam de programas de melhoramento, adotam o sistema de raiz-semente, pois este permite selecionar na população as características desejáveis (Andrade, 1993).

A tecnologia de produção de sementes de cenoura utilizada no Brasil, tem se refletido em baixa qualidade fisiológica das sementes devido, em parte, à métodos de produção inadequados (Nascimento \& Guedes, 1989), acarretando aumento na densidade de semeadura e, consequentemente, onerando ainda mais o insumo. Inúmeras causas influenciam a qualidade de sementes; no caso específico da cenoura, podemos 
destacar o tamanho, o peso e o grau de maturidade das sementes, sendo estes fatores variáveis mesmo entre sementes oriundas da mesma umbela.

Recentemente alguns autores têm relatado que a qualidade das sementes de cenoura seria mais dependente do grau de maturidade do embrião do que propriamente do tamanho da semente ou da umbela de origem. O conhecimento deste grau de maturidade é fundamental para se determinar o melhor momento da colheita, visando a obtenção de sementes de boa qualidade.

Coopeland \& Mc Donald (1985), relataram que a qualidade de sementes é composta por diversos componentes, incluindo a germinação, pureza, vigor e a sanidade. Características físicas como o tamanho, peso ou espessura também têm sido utilizadas; porém, a habilidade de aumentar a germinação de lotes de sementes baseada nas características fisicas é tida por alguns autores como limitada. No entanto, estudos têm sido realizados visando combinar as características fisicas com as características fisiológicas, associadas ainda à viabilidade e vigor dessas sementes.

Com o emprego dos métodos rotineiramente utilizados na análise de sementes, torna-se dificil a determinação do melhor momento para se proceder a colheita, pois uma vez que para avaliar a maturidade do embrião seria necessária a dissecação da semente, tornando o processo lento, exaustivo e impreciso. Porém, com o advento de técnicas não-destrutivas tornou-se possível avaliar as características da semente sem destruí-las, como por exemplo a utilização da técnica de análise de imagens, do uso de raio- $X$, da fluorescência de clorofila entre outras, tornando a tarefa de análise mais precisa, fácil e rápida, constituindo-se em métodos não convencionais de análise de sementes.

Este trabalho teve o objetivo de avaliar a qualidade fisica e fisiológica de sementes de cenoura provenientes de umbelas de primeira, segunda e terceira ordens, valendo-se de técnicas convencionais em análise de sementes como o teste de germinação, teste de deterioração controlada e teste de tetrazólio e, também, do uso de fluorescência de clorofila, um método novo que permite avaliar o grau de maturidade das sementes e, com o auxílio dos testes anteriormente mencionados, estabelecer uma relação entre a fluorescência de cada semente e sua qualidade. 


\section{REVISÃO DE LITERATURA}

A planta de cenoura, ao passar da fase vegetativa para a reprodutiva, emite uma haste ou pendão floral, terminando em uma inflorescência tipo umbela, denominada umbela central, primária ou de primeira ordem. A partir desta, surgem ramificações que terminarão em umbelas secundárias ou de segunda ordem; destas ramificações surgem novas que serão as umbelas terciárias ou de terceira ordem, e assim sucessivamente.

A antese normalmente se inicia nas flores periféricas da umbela central e precede a antese das demais umbelas. A porcentagem de flores masculinas aumenta nas umbelas de ordem mais elevada, atingindo $67 \%$ do total de flores nas umbelas de quarta ordem. Sendo assim, o rendimento em sementes, relativo ao número de flores, diminui à medida que aumenta a ordem da umbela.

Diversos autores, entre eles Krarup et al. (1976), têm relatado que a estrutura floral das plantas de cenoura se constitui em problema para a colheita de sementes, devido ao fato da maturação das distintas umbelas não ser uniforme. $O$ tempo de florescimento dentro de uma umbela varia de 7 a 10 dias e as diferenças no período de maturação entre as umbelas de uma mesma planta, é de aproximadamente três semanas, porém, dependendo das condições climáticas e da cultivar, pode atingir até 60 dias.

É possível presumir que a falta de maturação uniforme, não só produza diferenças no rendimento como também diferenças de viabilidade e de vigor dentro de um mesmo lote.

Bittencourt (1991), afirmou que a seqüência cronológica de florescimento entre as três ordens de umbelas causa variação na produção de sementes, quanto ao seu peso unitário e ao grau de maturidade por ocasião da colheita; assim, um lote de 
sementes comerciais pode apresentar diferentes níveis de maturidade, os quais se refletirão na porcentagem e na velocidade de germinação (Andrade, 1993).

Liberal (1976), em pesquisas realizadas com umbelíferas, indicou a existência de três tipos de problemas: sementes sem embrião, sementes com embrião rudimentar e sementes com dormência, sendo que o terceiro tipo é conseqüência do segundo. Andreoli \& Maguire (1987), estudando a variabilidade genética e a herdabilidade em relação às características de diferentes populações, verificaram que a porcentagem de sementes sem embrião variou de 21 a $30 \%$, nos dois anos pesquisados.

A influência do tamanho da semente e a presença de embriões, sobre a qualidade fisiológica de sementes de cenoura, foi estudada por Austin \& Longden (1967), Jacobsohn \& Globerson (1980) e Usik (1981), os quais observaram que as sementes de menor tamanho apresentavam menor porcentagem de germinação, de emergência em campo e de rendimento em relação às sementes de maior tamanho. A mesma ocorrência foi verificada por Krarup \& Villanueva (1977) e Gray \& Steckel (1983c), em que as sementes maiores apresentaram maior peso e embriões maiores e, por conseguinte, produziram plântulas mais vigorosas.

O tamanho da semente, em muitas espécies, é indicativo de sua qualidade fisiológica (Popinigis, 1985). As sementes maiores, normalmente, possuem embriões bem formados e com maiores quantidades de reservas (Carvalho \& Nakagawa, 1983); logo, num mesmo lote, as sementes grandes apresentam maior poder germinativo e vigor que as sementes menores, em decorrência do grau de desenvolvimento ou de maturidade de seu embrião.

Sabe-se, no entanto, que quanto maior a ramificação da umbela, menor é o tamanho do embrião de suas sementes. Essa diversidade, quanto ao tamanho do embrião e também ao peso das sementes, leva à diferenças nas produções de culturas originadas das diferentes umbelas (Castro \& Andrews, 1971; Reghin et al., 1986).

Umbelas de ordens superiores geralmente apresentam melhor poder germinativo; segundo Gray \& Steckel (1983b), este fato está intimamente relacionado ao comprimento do embrião destas sementes. Krarup \& Villanueva (1977), estudando a qualidade de sementes de diferentes ordens, observaram que a germinação das sementes 
das umbelas primárias e secundárias foi de $86 \%$ e as sementes de ordens inferiores foi de $73 \%$. Estes autores também observaram que o tamanho do embrião foi de 1,262 mm para as sementes provenientes de umbelas primárias, de 1,196 $\mathrm{nm}$ para as umbelas secundárias e 0,970 mm para as umbelas de ordens inferiores, e que existe uma correlação positiva entre o tamanho do embrião e a porcentagem de germinação.

Gray \& Steckel (1983a), avaliaram a relação entre o tamanho do embrião das sementes de cenoura e o grau de maturidade das mesmas, provenientes das diferentes umbelas, e verificaram que o processo de maturação é interrompido se as sementes forem colhidas precocemente e a qualidade das mesmas é afetada pela maior ocorrência de embriões imaturos. Uma possível explicação para tal seria que a alta densidade de plantas alteraria a faixa de tempo de florescimento das umbelas primárias. Desta forma, este aumento da variabilidade no tempo de florescimento alteraria o tempo de iniciação do crescimento do embrião, seu tamanho no momento da colheita e seu grau de maturidade, ocasionando aumento da variação do peso de plântulas a partir de sementes consideradas maduras.

Gray \& Steckel (1983c), relataram que sementes provenientes de umbelas secundárias atingem a maturidade muito tempo após as sementes provenientes de umbelas primárias; desta forma, aumentando-se a densidade de semeadura a produção de umbelas secundárias seria reduzida, diminuindo a desuniformidade de maturação. Porém, quando uma série de experimentos foi realizado, em diferentes anos, para examinar esta hipótese, os efeitos foram muito pequenos em relação ao que seria esperado (Gray \& Steckel, 1983b).

Andrade et al. (1993), verificaram que a ordem da umbela não afeta significativamente a qualidade fisiológica das sementes se as mesmas apresentarem uniformidade na maturação. Segundo Castro \& Andrews (1971), testes de vigor revelaram, predominantemente, que as sementes que amadurecem tardiamente no campo tendem a ser menos vigorosas do que aquelas que amadurecem mais cedo. Tal fato foi mais evidenciado pelo teste de deterioração controlada.

Mann \& Macgillivray (1949), correlacionando a germinação de vários lotes de sementes de cenoura com a freqüência de embriões normais, observaram que muitas 
sementes não germinavam, pelo fato de possuírem embriões imaturos. Borthwick (1931), afirmou que muitas destas sementes podem eventualmente germinar, se for dado tempo suficiente nos testes de germinação aos embriões imaturos, proporcionando assim o desenvolvimento dos mesmos.

Andreoli \& Maguire (1987), por meio do teste de tetrazólio, detectaram sementes de cenoura sem embrião. As sementes remanescentes, que permaneceram intactas ao final do teste de germinação, foram embebidas numa solução de tetrazólio $(0,5 \%)$ a $32^{\circ} \mathrm{C}$ por 24 horas; dissecadas longitudinalmente e examinadas em lupa estereoscópica (aumento de 60-80 vezes), verificaram que as sementes sem embrião apresentavam uma cavidade no endosperma.

Nas sementes sem embrião nota-se, tanto na secção longitudinal como na transversal, um estreitamento da cavidade que seria ocupada pelo embrião, embora externamente não haja diferença entre as sementes completamente formadas e aquelas sem embrião (Bittencourt, 1991). Segundo Andreoli \& Maguire (1987), a ocorrência de sementes sem embrião é um fator de ordem genética com alta herdabilidade e de origem e causa pouco conhecidas.

Andrade et al. (1996), desenvolveram estudos onde, em média, 5,0\% das sementes não apresentavam embrião, $1,1 \%$ com embrião de tamanho rudimentar $\mathrm{e}$ $14,8 \%$ com embriões mortos e infectados, tendo o comprimento médio das sementes variado entre 1,5 a $3,5 \mathrm{~mm}$ e o do embrião de 1,0 a $1,5 \mathrm{~mm}$ aproximadamente. A ocorrência de sementes sem embrião e de embrião rudimentar foi atribuída principalmente à maturação desuniforme das diferentes umbelas.

Não havendo alterações na forma da semente ou em seu peso, devido ao fato do peso do embrião ser ínfimo em comparação com o peso total da semente, não é possível eliminar as sementes sem embrião ou com embrião rudimentar no processo de beneficiamento.

A correlação entre as características fisicas e fisiológicas das sementes com a emergência em campo, tem sido utilizada para determinar a qualidade de sementes. Tais características se relacionam melhor com a emergência do que com os resultados do teste de germinação conduzido em laboratório. Entretanto, Hampton \& Coolbear (1990), 
argumentaram que os testes de vigor não substituem 0 de germinação, mas complementam as informações fornecidas por este.

Diferenças na velocidade de germinação e na variação do peso de plântulas são positivamente associadas com diferenças no periodo de florescimento (Gray \& Steckel, 1983a). Desta forma, atrasando-se o período de colheita esta variabilidade poderia ser reduzida e, consequentemente, proporcionar redução nas diferenças no nível de uniformidade de maturação e viabilidade, pois o tempo de florescimento seria estendido, evitando-se uma prematura interrupção no crescimento do embrião e da semente.

Testes de germinação de sementes de cenoura são, usualmente, conduzidos por cerca de duas semanas, sendo que a maioria das sementes germina durante a primeira semana; porém, ao final de duas semanas, muitas das sementes não germinadas estão ainda firmes e aparentemente em boas condições. Borthwick (1931), tomou estas sementes, cortou-as longitudinalmente e examinou-as ao microscópio. Observou que quase todas as sementes tinham um endosperma firme e de tamanho comum. Verificou, no entanto, que freqüentemente o embrião de tais sementes não era totalmente desenvolvido, apresentando-se muito pequeno e pouco visível. No caso particular da cenoura, segundo Bittencourt (1991), tal ocorrência poderia ser conseqüência de embrião rudimentar. Este fato se constitui em problema, pois os métodos rotineiramente empregados em laboratórios de análise de sementes não informam as condições em que se encontra o embrião, sendo necessário procoder a dissecação das sementes, tornando o trabalho lento e de dificil interpretação, pois as mensurações de tamanho de embrião, tomadas em régua graduada em milímetros, estão sujeitas a uma grande margem de erro por parte do analista.

Para tal, pesquisas recentes e acurados sistemas automatizados para a análise de sementes têm sido desenvolvidos, tendo como base a análise de imagens. Esta é uma técnica atrativa e facilmente adaptável a muitas circunstâncias, podendo proporcionar uma análise da qualidade das sementes em tempo real e de forma não dispendiosa. 
A aplicação da análise de imagens, na agricultura e na ciência de plantas, tem crescido consideravelmente nos últimos anos, com trabalhos desenvolvidos por pesquisadores como Zayas et al. (1990) e Vooren \& Heijden (1993).

Os primeiros trabalhos sobre a utilização de análise de imagem, em Tecnologia de Sementes, referiam-se a separações entre sementes de espécies cultivadas e sementes de espécies daninhas, através de sua forma e tamanho (Keefe \& Draper, 1986).

A análise de imagens constitui-se num método, não convencional, para a determinação das características das sementes. A referida técnica proporciona a análise das sementes sem destrui-las, sendo possível comprovar, por exemplo, através do teste de germinação, quais danos detectados pelas imagens são realmente importantes, em função da análise individual de cada semente.

Da mesma forma, a fluorescência de clorofila proporciona que se determine a qualidade fisiológica da semente e, como se trata de método não destrutível, o seu desempenho poderá ser comprovado através do teste de germinação ou de vigor.

$\mathrm{O}$ conhecimento da fase de desenvolvimento da semente na qual atingem o máximo de qualidade é assunto de alguma controvérsia. Steckel et al. (1989), colheram sementes de cenoura em diferentes fases de maturação e observaram uma diminuição no conteúdo total de clorofila da semente durante seu desenvolvimento. Coincidentemente, com a diminuição em conteúdo de clorofila total, o desempenho de germinação das sementes de cenoura aumentou. Por causa desta correlação, Steckel et al. (1989), propuseram um teste de campo simples, no qual se usa cartões coloridos para avaliar o conteúdo de clorofila de extratos de sementes, visando calcular a data de colheita. Para a maioria das espécies de sementes, a quantidade de clorofila diminui durante o processo de maturação. Ao mesmo tempo, a cor da semente muda de verde para uma cor característica dependendo da espécie e do cultivar. Este processo é chamado de descoloração, porém, esta alteração na cor da semente ainda não é totalmente conhecida.

Um lote pode conter sementes em fases de maturação variadas. As diferenças em maturidade entre sementes individuais podem ficar até maiores, devido à 
condições adversas de clima, que precedem a colheita, ou à diferenças de planta para planta.

É conhecido que a clorofila apresenta fluorescência quando sua molécula está excitada com um comprimento de onda determinado (Nobel, 1970). Em estudos recentes usando fluorescência de clorofila, tem sido verificado diferenças em quantidades relativas de clorofila em sementes individuais em um mesmo lote de sementes. Jalink et al. (1998a), baseados na magnitude do sinal de fluorescência de clorofila, dividiram sementes em várias classes de maturidade, obtendo resultados em que a fluorescência de clorofila pode ser usada para melhor separar sementes de repolho de diferentes graus de maturidade, separando sementes mortas, de viáveis e, dentre estas, as de maior qualidade fisiológica para fins de semeadura, proporcionando assim um estande uniforme.

Tkachuk \& Kuzina (1982), trabalhando com sementes de colza, verificaram que dependendo do grau de maturidade, as sementes apresentam diferentes teores de clorofila; este fato deve ser levado em consideração, pois durante o processo de extração de óleo o excesso de clorofila, encontrado em sementes imaturas, irá conferir ao óleo uma coloração esverdeada, depreciando o valor comercial do produto. Com base nesta preocupação foram conduzidos trabalhos onde a quantificação de clorofila presente nas sementes foi realizada usando-se um espectofotômetro, com espectro entre 630 a $754 \mathrm{~nm}$ e a região do infra-vermelho entre 1640 a $2176 \mathrm{~nm}$. Foi elaborada uma equação que possibilitasse relacionar esses resultados obtidos com os testes normalmente empregados para a extração de clorofila. Desta forma, este novo método, pelo fato de não ser destrutivo, possibilita que as sementes intactas possam ser utilizadas em outros testes.

Vertucci et al. (1985), estudaram dois fenômenos relacionados com a fluorescência em sementes de ervilha, quais sejam o espectro de excitação de fluorescência e a indução de fluorescência. As mensurações foram realizadas com o auxílio de um fluorômetro (Branker SF -10), sendo as leituras efetuadas entre 300 e 700 $\mathrm{nm}$. Concluíram que as propriedades da fluorescência mudam com a variação do teor de água dos tecidos vegetais; quando os tecidos encontram-se normalmente hidratados a 
transferência de energia e o transporte de elétrons aumentam e a fluorescência é máxima.

Ward et al. (1992), realizaram estudos visando reduzir a grande variação na maturidade de sementes de colza no momento da colheita, pois fatores como a temperatura, durante o processo de maturação das sementes, podem alterar sua taxa de clorofila. Verificaram contudo, que as sementes colhidas das fileiras laterais da umbela principal continham teores de clorofila maiores em relação às sementes provenientes do centro da umbela principal; como o número de sementes provenientes das fileiras laterais é maior, isto proporciona grande variação entre sementes de um mesmo lote e mesmo entre sementes de uma mesma planta.

Ward et al. (1995), afirmaram que a degradação da clorofila em sementes é pouco conhecida. Autores como Ward (1990) e Mc Gregor (1991), em seus estudos, concluíram que os níveis de clorofila presentes nas sementes na colheita e a qualidade das mesmas, são afetados igualmente pelo genótipo e pelas condições climáticas, notadamente a temperatura no período de maturação das sementes. Obtiveram, ainda, resultados que indicam que a degradação da clorofila está relacionada com os níveis de teor de água e etileno, atuando estes três fatores simultaneamente durante a maturação das sementes, porém sem que um fator interfira no outro. Duas cultivares podem apresentar o mesmo teor de clorofila sem que apresentem necessariamente a mesma taxa de etileno ou de teor de água.

Taylor (1991), desenvolveu um sistema onde sementes submetidas a um processo de hidratação e secagem eram examinadas sob luz ultra-violeta e separadas manualmente em duas frações de sementes que apresentavam ou não fluorescência. Semeando as sementes que não apresentavam fluorescência observou um grande percentual de plântulas normais para todos os lotes analisados. Já a fração de sementes que apresentavam fluorescência continham uma alta percentagem de sementes mortas e de plântulas anormais.

Em escala comercial já estão surgindo alguns equipamentos que permitem aplicar a tecnologia de separar sementes de forma rápida e precisa, através de características como diferenças de cor e de fluorescência ou não de clorofila. As 
sementes rejeitadas são eliminadas através de um dispositivo de jato de ar comprimido, com controle elétrico, deixando passar as sementes de boa qualidade (Cabrera \& Diaz, 1991).

Taylor et al. (1993), realizaram estudos visando quantificar a emissão de fluorescência de clorofila em sementes de repolho usando um espectofotômetro ótico, separando manualmente cada lote de sementes em frações de sementes fluorescentes e não fluorescentes. O comprimento de onda da luz foi de $365 \mathrm{~nm}$. O espectro inicial da fluorescência foi caracterizado entre 350 e $650 \mathrm{~nm}$, sendo a percentagem da transmitância convertida com base em um padrão inicial conhecido. Após selecionadas, as sementes foram fotografadas sob luz ultra-violeta e a porcentagem daquelas que apresentaram fluorescência foi determinada. Assim, foi possível calibrar o equipamento para efetuar uma separação eficiente. Foram observados incrementos nos valores de germinação de sementes nos lotes submetidos a esta seleção, sendo os maiores incrementos nos lotes de média e alta qualidade. A eficácia da seleção pela cor foi confirmada através de inspeção visual sob luz ultra-violeta; concluíram que a tecnologia da seleção através da coloração sob luz ultra-violeta pode ser empregada visando a melhoria da qualidade do lote de sementes de repolho, pela retirada das sementes de baixa qualidade, ou seja, aquelas com altos teores de clorofila.

Mills et al. (1999), efetuaram estudos com sementes de lentilha visando estabelecer relações entre sua coloração, bem como suas variações, com alterações em seu $\mathrm{pH}$ e condutividade elétrica, relacionando-se, em última instância, com a germinação final. Observaram que mudanças no $\mathrm{pH}$, na condutividade elétrica e na germinação estavam relacionadas com alterações na cor das sementes de lentilha e podem ser usadas como um método para avaliar sua qualidade, sendo as sementes examinadas com base na intensidade de sua coloração marrom. 


\section{MATERIAL E MÉTODOS}

\subsection{Sementes}

As sementes de cenoura (Daucus carota L.), cv. Kuronan, utilizadas no presente trabalho foram produzidas e beneficiadas pela empresa Hortec Sementes Ltda, localizada no município de Bagé, RS. A colheita e o beneficiamento foram realizados de maneira que se mantivessem individualizadas as frações das sementes produzidas pelas umbelas das ordens primária, secundária e terciária.

\subsection{Teor de água}

Para a determinação do teor de água foram tomadas amostras de $10 \mathrm{~g}$ de sementes de cada umbela de origem, as quais foram homogeinizadas em divisor de solo e separadas em duas repetições. As repetições foram colocadas em cápsulas metálicas, previamente pesadas e submetidas à secagem em estufa a $105^{\circ} \mathrm{C}$ por $24 \mathrm{~h}$. A seguir calculou-se o teor de água (\%) com base no peso úmido (BRASIL, 1992).

\subsection{Peso de 1000 sementes}

Para a determinação do peso de 1000 sementes, foram tomadas oito repetições de 100 sementes, para cada uma das ordens das umbelas de origem, de acordo com a metodologia descrita pelas Regras para Análise de Sementes (BRASIL, 1992). 


\subsection{Medida de fluorescência de clorofila}

Realizada mediante a utilização de um feixe de luz (laser - Hewlett Packard HLMP $-8150, \lambda$ máx. $=650 \mathrm{~nm}$ ), tendo acoplado um filtro de interferência (lente $\lambda$ máx. $=650 \mathrm{~nm}$ ), que reflete aproximadamente $50 \%$ da luz, concentrando o feixe sobre as sementes. Desta forma a molécula de clorofila é excitada, sendo possível registrar sua fluorescência que é capturada pela mesma lente, dirigindo novamente aproximadamente $50 \%$ da luz para um fotodiodo. A $690 \mathrm{~nm}$, faixa principal no espectro de fluorescência de clorofila (FC), parte da fluorescência é reabsorvida pela clorofila causando efeitos não-lineares entre a quantidade de clorofila e a magnitude de fluorescência (Jalink et al., 1998b). Antes de atingir o fotodiodo a luz atravessa um novo filtro de interferência de $730 \mathrm{~nm}$, pois nesta região de comprimento de onda a reabsorção da fluorescência é pequena.

Com esta combinação de dois filtros de interferência de $650 \mathrm{~nm}$ e $730 \mathrm{~nm}, 0$ sinal, devido a luz captada, foi reduzido a uma corrente de cerca de 1 pico Ampère ( $\mathrm{pA}$ ) que é desprezível comparado aos sinais de fluorescência medidos. Utilizando-se um amplificador (Stanford Research SR 830), a luz modulada é convertida a uma corrente captada pelo fotodiodo em um sinal que é proporcional à intensidade de fluorescência.

Após a mensuração de fluorescência de clorofila de 10.000 sementes, tendo a leitura variado entre os valores de 0 e $218 \mathrm{pA}$, optou-se por classificar cada um dos lotes em três classes de fluorescência: baixa (10-20 pA), média $(20-40 \mathrm{pA})$ e alta $(>40$ $\mathrm{pA})$.

\subsection{Teste de germinação}

O teste padrão de germinação foi conduzido para cada uma das ordens das umbelas de origem e para cada uma das classes de fluorescência de clorofila, utilizandose discos de papel filtro em mesas de germinação, a uma temperatura de $20^{\circ} \mathrm{C}$, com exposição a um regime de $8 \mathrm{~h}$ de luz e $16 \mathrm{~h}$ de escuro. A avaliação dos resultados foi realizada conforme as instruções das Regras para Análise de Sementes (BRASIL, 1992), 
sendo a análise dos resultados realizada com o emprego do programa de computador "SEED CALCULATOR", desenvolvido no 'Wageningen Seed Center' (Jalink \& Schoor, 2000).

\subsection{Velocidade de germinação}

Este teste foi realizado concomitantemente com o teste de germinação, sendo a análise da velocidade de germinação realizada de acordo com o programa de computador "SEED CALCULATOR", desenvolvido no 'Wageningen Seed Center' (Jalink \& Schoor, 2000), onde a velocidade de germinação foi determinada, em dias, avaliando-se diariamente o número de sementes que apresentavam a protrusão da radícula; considerou-se como indicação de vigor o momento (dias) em que $50 \%$ das sementes apresentavam a protrusão da radícula.

\subsection{Teste de deterioração controlada}

O teste de deterioração controlada foi executado para cada uma das ordens das umbelas de origem e para cada uma das classes de fluorescência de clorofila, utilizando-se a metodologia indicada pela INTERNATIONAL SEED TESTING ASSOCIATION (1996), modificada nos seguintes aspectos: a) as sementes foram colocadas em placas de Petry abertas, em um gabinete com temperatura de $20^{\circ} \mathrm{C}$ e $85 \%$ de umidade relativa do ar, pelo período de três dias, determinado-se em seguida seu teor de água; b) as sementes, acondicionadas em embalagens aluminizadas fechadas, foram colocadas em estufa a $40^{\circ} \mathrm{C}$ por um período de três dias; c) antes de se proceder o teste de germinação, como descrito no item 3.5 , as sementes foram colocadas, em placas de Petry abertas, em um gabinete com temperatura de $20^{\circ} \mathrm{C}$, por um período de dois dias, para equalizar o seu teor de água. 


\subsection{Teste de tetrazólio}

O teste de tetrazólio foi executado para cada uma das ordens das umbelas de origem e para cada uma das classes de fluorescência de clorofila. As sementes foram previamente acondicionadas em gerbox com papel filtro, umedecido com água destilada na proporção de 2,5 vezes o seu peso seco, durante 60 minutos a $25^{\circ} \mathrm{C}$. Após este período, foram seccionadas por um corte longitudinal ao longo do lado do embrião e, imediatamente, embebidas na solução de tetrazólio a $0,1 \%$, durante 60 minutos a $35^{\circ} \mathrm{C} \mathrm{e}$, finalmente, lavadas em água corrente, após a qual eram realizadas as avaliações, segundo metodologia descrita por Andrade et al. (1996). Foram avaliadas 16 repetições de 25 sementes por classe de fluorescência de clorofila. O percentual de sementes viáveis foi determinado e também a caracterização das categorias de sementes com embriões de tamanho normal, rudimentar, mortos e/ou ausentes, através da utilização de microscópio estereoscópico com uma ampliação entre 20 e 100 vezes o tamanho original. As fotos foram obtidas através do uso de uma câmera digital Philips, modelo $56474 \mathrm{CCD}$, acoplada ao microscópio e interligada ao computador.

\subsection{Comprimento do embrião}

Para a avaliação do comprimento dos embriões procedeu-se como descrito no item 3.8 (teste de tetrazólio), sendo que após a lavagem em água realizou-se a extração dos embriões. Estes foram mantidos em água destilada até o momento de realizar a mensuração, utilizando-se uma placa reticulada, graduada em mm e o auxílio de um microscópio estereoscópico com uma ampliação entre 20 e 100 vezes o tamanho original. As fotos foram obtidas através do uso de uma câmera digital Philips, modelo $56474 \mathrm{CCD}$, acoplada ao microscópio e interligada ao computador. 


\subsection{Delineamento estatístico}

O delineamento estatístico adotado neste trabalho foi $o$ inteiramente casualizado, por ser mais apropriado para experimentos em ambientes controlados. A análise estatística dos dados foi realizada utilizando-se o teste de Student, ao nível de significância de 0,05, conforme o programa de computador "SEED CALCULATOR", desenvolvido no 'Wageningen Seed Center' (Jalink \& Schoor, 2000). 


\section{RESULTADOS E DISCUSSÃO}

\subsection{Teor de água, peso de 1000 sementes e comprimento do embrião.}

Os resultados referentes ao teor de água, peso de 1000 sementes e comprimento do embrião das sementes provenientes das umbelas primária, secundária e terciária podem ser observados na Tabela 1.

Quanto ao teor de água não foram observadas diferenças entre as sementes, independente da umbela de origem; tal fato pode ser explicado em virtude das sementes, após a colheita manual, terem sofrido secagem natural, até atingirem um valor próximo à $6 \%$ de umidade, quando efetuou-se o acondicionamento em embalagens impermeáveis.

Observou-se diferença significativa entre as sementes das umbelas primária e secundária em relação à terciária para os valores obtidos no peso de 1000 sementes. Resultados semelhantes têm sido relatados por diversos autores, Bittencourt (1991), afirmou que a seqüência cronológica de florescimento, observada entre as diferentes umbelas, causa variação na produção de sementes em relação ao seu peso unitário e ao grau de maturidade por ocasião da colheita. Desta forma, em lotes de sementes comerciais, a ocorrência de sementes com tais diferenças irá influenciar negativamente a velocidade de germinação e o percentual de plântulas normais (Andrade, 1993).

$\mathrm{Na}$ Tabela 1 podemos verificar diferenças significativas entre $\mathrm{O}$ comprimento médio dos embriões das três diferentes umbelas. As sementes das umbelas primária, secundária e terciária apresentam, respectivamente valores médios de comprimento do embrião de 2,048 mm, $1.912 \mathrm{~mm}$ e $1,685 \mathrm{~mm}$. Podemos considerar o comprimento do embrião como um indicativo da qualidade fisiológica das sementes pois, normalmente, as sementes mais pesadas apresentam um tamanho também maior e 
por conseguinte, embriões maiores e bem formados. Resultados semelhantes foram relatados por Krarup \& Villanueva (1977), os quais estudando a qualidade de sementes de diferentes ordens florais, observaram que o comprimento médio dos embriões foi de 1,262 $\mathrm{mm}$ para as sementes da umbela primária, de 1,196 $\mathrm{mm}$ para as sementes da umbela secundária e de $0,970 \mathrm{~mm}$ para as sementes da umbela terciária. Andrade et al. (1993), obtiveram comprimentos médios que variaram entre $1,500 \mathrm{~mm}$ para os embriões de sementes de umbela primária a 1,000 mm para embriões de sementes de umbela terciária. Verifica-se que diferenças significativas no tamanho de embriões entre as diferentes umbelas tem sido uma constante, indicando que este parâmetro pode ser usado para avaliar a qualidade das sementes de cenoura, conforme citado por Gray et al. (1986).

Keefe \& Draper (1986), afirmaram que lotes de sementes de cenoura produzidas em condições de cultivos uniformes (temperatura, densidade, etc.), produzem embriões de tamanho similar. Inversamente, lotes de sementes com variação de tamanho de embriões proporcionam o estabelecimento de campos desuniformes. Neste estudo, a variação observada no tamanho dos embriões está diretamente relacionada com o grau de maturidade destes.

Tabela 1. Teor de água (TA), peso de 1000 sementes (P 1000) e comprimento de embrião (CE) de sementes oriundas das umbelas primária, secundária e terciária .

\begin{tabular}{cccc}
\hline Umbela & TA $(\%)$ & P $1000(\mathrm{~g})$ & CE $(\mathrm{mm})$ \\
\hline Primária & 6,8 & $2,048 \mathrm{a}^{*}$ & $1,721 \mathrm{a}$ \\
Secundária & 6,8 & $1,912 \mathrm{a}$ & $1,312 \mathrm{~b}$ \\
Terciária & 7,0 & $1,685 \mathrm{~b}$ & $1,109 \mathrm{c}$
\end{tabular}

*Médias seguidas por letras distintas, nas colunas, diferem pelo teste de Student ao nível de significância de 0,05 . 


\subsection{Fluorescência de clorofila}

A fluorescência de clorofila $(\mathrm{FC})$ apresentou sinais que variaram entre $0 \mathrm{e}$ $218 \mathrm{pA}$, sendo que a grande parte dos sinais foram captados na faixa de 5 a $40 \mathrm{pA}$. Observou-se uma redução no número de sementes para os valores mais altos de fluorescência de clorofila.

Baseado nos sinais de fluorescência de clorofila, cada umbela foi dividida em três classes, quais sejam, baixa (10-20 pA), média (20-40 pA) e alta (>40 pA). A proporção de sementes de cada umbela, para cada uma das três classes de fluorescência de clorofila, pode ser observada na Tabela 2.

Tabela 2. Percentual de semente (\%) e peso de 1000 sementes (g) das umbelas primária, secundária e terciária em cada classe de fluorescência de clorofila (FC), baixa (10-20 pA), média (20-40 pA) e alta (> $40 \mathrm{pA})$.

\begin{tabular}{|c|c|c|c|c|c|c|}
\hline \multirow{3}{*}{ Classe FC } & \multicolumn{6}{|c|}{ Umbela } \\
\hline & \multicolumn{2}{|c|}{ Primária } & \multicolumn{2}{|c|}{ Secundária } & \multicolumn{2}{|c|}{ Terciária } \\
\hline & $(\%)$ & (g) & $(\%)$ & (g) & $(\%)$ & (g) \\
\hline Baixa & 64 & $2,060 \mathrm{aA}$ & 66 & $1,914 \mathrm{aB}$ & 23 & $1,689 \mathrm{aC}$ \\
\hline Média & 28 & $2,044 \mathrm{aA}$ & 17 & $1,908 \mathrm{aA}$ & 49 & $1,675 \mathrm{aB}$ \\
\hline Alta & 8 & $2,038 \mathrm{aA}$ & 17 & $1,865 \mathrm{aB}$ & 28 & $1,597 \mathrm{aC}$ \\
\hline
\end{tabular}

*Médias seguidas por letras minúsculas distintas nas colunas e letras maiúsculas nas linhas diferem pelo teste de Student ao nível de significância de 0,05.

$\mathrm{O}$ exame da Tabela 2 permite verificar que, para as umbelas primária e secundária, aproximadamente $65 \%$ das sementes encontravam-se na classe de baixa fluorescência de clorofila. Já a umbela terciária possuía $23 \%$ das sementes na classe de baixa fluorescência de clorofila, $49 \%$ na classe de média fluorescência de clorofila e $28 \%$ na classe de alta fluorescência de clorofila. Tal fato já foi citado por diversos 
autores, como Ward et al. (1992) e Ward et al. (1995), que estudando a relação entre os conteúdos de clorofila e a maturação em sementes de repolho e rabanete, obtiveram histogramas de freqüência de fluorescência de clorofila, onde a maioria das sementes encontrava-se entre um valor de baixo e médio, demonstrando que um mesmo lote de sementes não é uniforme para a quantia de clorofila, provavelmente devido a uma variação de maturidade entre sementes individuais.

Foram observadas pequenas diferenças numéricas no peso de 1000 sementes entre as diferentes classes de fluorescência de clorofila, dentro de cada umbela (Tabela 2) e diferenças significativas entre o peso das diferentes umbelas como já apresentado na Tabela 1, o que também foi observado por Jalink et al. (1998), realizando trabalhos com sementes de repolho.

Possivelmente, as sementes de cenoura sofrem um aumento em seu peso durante a última fase do processo de maturação e, as sementes maduras sejam mais eficientes no processo de redução dos teores de clorofila. Vertucci et al. (1985), trabalhando com sementes de ervilha concluíram que as propriedades de fluorescência mudam com a variação do teor de água dos tecidos vegetais; como se sabe, na maturidade ocorre uma redução no teor de água nas sementes.

Ward et al. (1992), em estudos realizados com sementes de colza, relataram que diferentes cultivares apresentaram taxas de clorofila semelhantes quando cultivadas em condições semelhantes; contudo, fatores como a temperatura durante o processo de maturação das sementes podem alterar a taxa de clorofila no momento da colheita. Observaram ainda que as sementes colhidas das fileiras laterais da umbela principal continham teores de clorofila maiores em relação às sementes provenientes do centro da umbela principal, provocando grande variação entre sementes de uma mesma planta no momento da colheita em função do maior número de sementes provenientes das fileiras laterais.

A diferença em relação à cor das sementes entre as diferentes classes de fluorescência de clorofila é visível a olho nu (Figuras 1 e 2), tal diferença na cor indica que a clorofila está localizada no tegumento da semente. Resultados semelhantes foram relatados por Werker (1997), para sementes de diversas espécies. Embora as três classes 


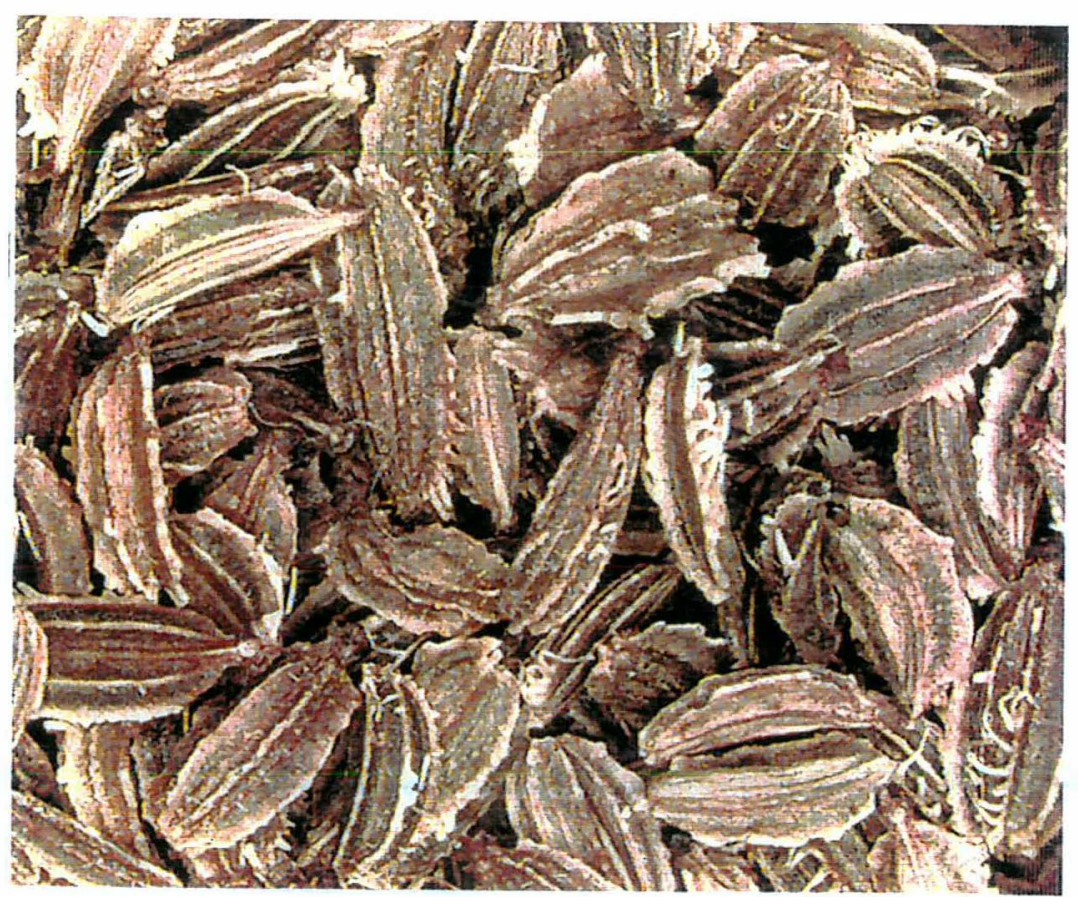

Figura 1 - Fração de sementes de baixa FC.

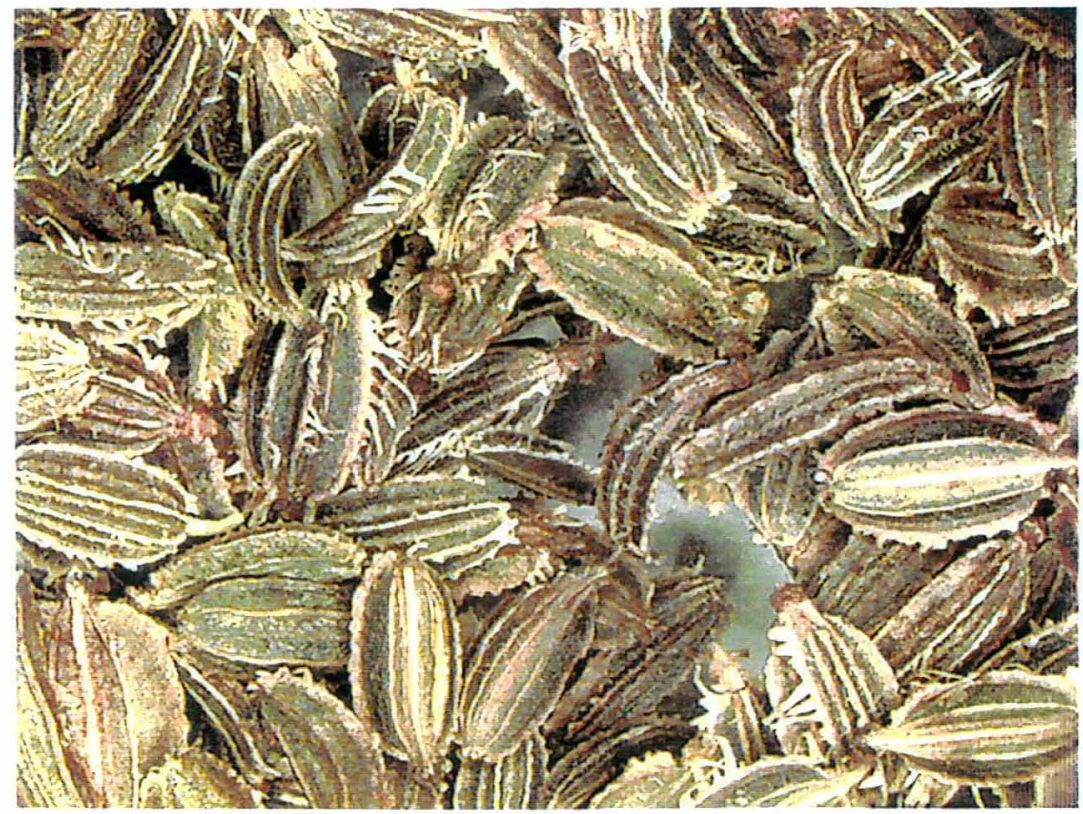

Figura 2 - Fração de sementes de alta FC. 
de fluorescência de clorofila tenham diferido na cor, cada classe possuía sementes com coloração semelhante mas com um valor diferente de sinal de fluorescência de clorofila.

Aparentemente, sementes de maturidades diferentes que parecem ter a mesma coloração à olho nu, podem conter diferentes quantidades de clorofila. A clorofila na semente é fotossinteticamente inativa, porque o metabolismo da semente é reduzido durante o processo de maturação. Consequentemente, ao contrário de folhas e frutas úmidas, as sementes apresentam o que se chamou "fluorescência variável", devido à atividade fotossintética e que é comumente medida com uma ampliação da modulação de pulsação (PAM), em um fluorômetro, conforme relatado por Schreiber (1986).

\subsubsection{Germinação}

Os resultados obtidos no teste de germinação podem ser observados na Tabela 3. Diferenças estatísticas significativas foram encontradas, dentro de cada umbela, para as diferentes classes de fluorescência de clorofila. A germinação das sementes está relacionada com a quantidade de clorofila presente no tegumento da semente, ou seja, sementes que apresentam baixa fluorescência de clorofila atingiram valores de germinação de $97 \%$ para umbela primária, $96 \%$ para umbela secundária e 92\% para umbela terciária. Já para a classe de alta fluorescência de clorofila foram obtidos $83 \%$ de germinação para a umbela primária, $80 \%$ para a umbela secundária e $83 \%$ para a umbela terciária. Resultados semelhantes foram obtidos por Andrade et al. (1993), que verificaram que a ordem da umbela não afeta significativamente a qualidade fisiológica das sementes se as mesmas apresentarem uniformidade na maturação.

Johnson-Flanagan \& Thiagarajah (1990), afirmaram que a baixa qualidade das sementes com altos valores de fluorescência de clorofila está diretamente relacionada com a natureza imatura destas sementes. Taylor (1991), estudando a fluorescência de sementes, com o auxílio de luz ultra-violeta, observou que sementes que não apresentaram fluorescência proporcionaram alto percentual de plântulas normais para todos os lotes analisados; já a fração de sementes que apresentaram fluorescência proporcionaram alta percentagem de sementes mortas e de plântulas anormais. 
Tabela 3. Germinação $(G)$ e velocidade de germinação (VG) de sementes de cenoura oriundas de três diferentes umbelas e em três classes de fluorescência de clorofila (FC) baixa (10-20 pA), média $(20-40 \mathrm{pA})$ e alta $(>40 \mathrm{pA})$.

\begin{tabular}{cccc}
\hline Umbela & FC & G(\%) & VG (dias) \\
\hline Primária & Baixa & $97 \mathrm{a}^{*}$ & $1,74 \mathrm{a}$ \\
& Média & $89 \mathrm{~b}$ & $1,97 \mathrm{~b}$ \\
& Alta & $83 \mathrm{c}$ & $2,45 \mathrm{c}$ \\
\hline Secundária & Baixa & $96 \mathrm{a}$ & $1,95 \mathrm{a}$ \\
& Média & $90 \mathrm{~b}$ & $1,99 \mathrm{a}$ \\
& Alta & $80 \mathrm{c}$ & $2,54 \mathrm{~b}$ \\
\hline Terciária & Baixa & $92 \mathrm{a}$ & $1,60 \mathrm{a}$ \\
& Média & $90 \mathrm{a}$ & $2,00 \mathrm{~b}$ \\
& Alta & $83 \mathrm{~b}$ & $2,42 \mathrm{c}$ \\
\hline
\end{tabular}

*Médias seguidas por letras distintas, nas colunas, diferem pelo teste de Student ao nível de significância de 0,05.

Deste modo, a fluorescência de clorofila pode ser usada como um método de seleção que vise incrementar valores de germinação das sementes de cenoura pela retirada das sementes de baixa qualidade, ou seja, aquelas com altos teores de clorofila. Tal proposição está de acordo com os resultados obtidos por Taylor et al. (1993), que observaram incrementos nos valores de germinação de sementes de repolho nos lotes submetidos a esta seleção, sendo os maiores incrementos nos lotes de média e alta qualidade.

\subsubsection{Velocidade de germinação}

Para a velocidade de germinação (Tabela 3), foi constatada a ocorrência de diferenças estatísticas significativas entre as diferentes classes de fluorescência de 
clorofila, dentro de cada umbela, com exceção das classes de baixa e média fluorescência de clorofila da umbela secundária que não diferiram entre si. As sementes das classes com menor fluorescência de clorofila apresentaram melhores índices de vigor pelo fato de germinarem mais rapidamente do que as sementes das classes com maior fluorescência de clorofila.

Para Salter et al. (1981), a variação no peso de raízes de cenoura na colheita está diretamente relacionada com o peso das plântulas logo após a emergência e esta, por sua vez, está relacionada diretamente com o tempo de emergência, que será menor quanto maior for a qualidade das sementes. Benjamin (1982; 1988), realizou trabalhos onde constatou que diferenças na velocidade de emergência, variáveis de 3 a 7 dias, estavam diretamente relacionada com a maturidade das sementes.

A relação obtida entre a fluorescência de clorofila e a velocidade de germinação, ou seja, menor fluorescência de clorofila maior velocidade, obtida neste trabalho, é reforçada pela afirmação de Gray \& Steckel (1986), de que diferenças na velocidade de germinação e na variação do peso de plântulas são positivamente associadas com diferenças no tempo de florescimento. Desta forma, uma colheita mais tardia poderia reduzir esta variabilidade, pois o período de florescimento seria estendido, evitando-se uma prematura interrupção no crescimento do embrião e da semente.

\subsubsection{Deterioração controlada}

O efeito da fluorescência de clorofila na qualidade das sementes torna-se mais evidente no teste de deterioração controlada (Tabela 4). As diferenças significativas podem ser observadas quando são comparadas as três classes de fluorescência de clorofila com o controle, ou seja, a fração original de cada umbela que não passou pelo processo de seleção por fluorescência de clorofila. As sementes da classe de baixa fluorescência de clorofila apresentaram um incremento em sua germinação, de 7 a 10 pontos percentuais, para as três umbelas em relação ao controle, enquanto que as sementes da classe de média fluorescência de clorofila não apresentaram diferença em relação ao controle e, as sementes da classe de alta 
fluorescência de clorofila, apresentaram decréscimo na germinação quando comparadas ao controle. Conclui-se, concordando com Johnson-Flanagan \& Thiagarajah (1990), que sementes com valor de fluorescência de clorofila elevado representam as sementes imaturas ou aquelas de menor vigor, em oposição às sementes com menores valores de fluorescência de clorofila que representam as sementes mais velhas na planta ou aquelas com maior vigor.

Segundo Castro \& Andrews (1971), testes de vigor, como a deterioração controlada indicam, predominantemente, que as sementes que amadurecem tardiamente no campo tendem a ser menos vigorosas que as sementes que amadurecem mais cedo.

Tabela 4. Efeito da deterioração controlada na germinação (G) e na velocidade de germinação (VG), de sementes de cenoura, oriundas das umbelas primária, secundária e terciária, em três classes de fluorescência de clorofila (FC) baixa (10-20 pA), média (20-40 pA) e alta (> $40 \mathrm{pA})$.

\begin{tabular}{cccc}
\hline Umbela & FC & G(\%) & VG (dias) \\
Primária & Controle & $81 \mathrm{~b}^{*}$ & $1,83 \mathrm{~b}$ \\
& Baixa & $90 \mathrm{a}$ & $1,80 \mathrm{~b}$ \\
& Média & $84 \mathrm{~b}$ & $1,80 \mathrm{~b}$ \\
& Alta & $77 \mathrm{c}$ & $2,53 \mathrm{a}$ \\
Secundária & Controle & $81 \mathrm{~b}$ & $1,81 \mathrm{~b}$ \\
& Baixa & $88 \mathrm{a}$ & $1,78 \mathrm{~b}$ \\
& Média & $80 \mathrm{~b}$ & $1,81 \mathrm{~b}$ \\
& Alta & $76 \mathrm{c}$ & $2,57 \mathrm{a}$ \\
Terciária & Controle & $77 \mathrm{~b}$ & $1,99 \mathrm{~b}$ \\
& Baixa & $87 \mathrm{a}$ & $1,78 \mathrm{c}$ \\
& Média & $80 \mathrm{~b}$ & $1,79 \mathrm{c}$ \\
& Alta & $70 \mathrm{c}$ & $2,60 \mathrm{a}$
\end{tabular}

*Médias seguidas por letras distintas, nas colunas, diferem pelo teste de Student ao nível de significância de 0,05. 
Desta forma, usando-se uma combinação de tecnologia de luz (condução de luz com alto poder de direcionamento) com o uso de filtros, melhorando a relação sinal/conteúdo, pode-se medir a clorofila da semente com uma sensibilidade e seletividade mais alta do que por métodos convencionais como cartões coloridos (comparação) ou medidas do espectro de reflexão (Tkachuk \& Kuzina, 1982).

A deterioração de sementes, durante o armazenamento, foi freqüentemente relacionada com a oxidação de radicais livres, danificando proteínas, ácidos nucleicos e membranas (De Vos et al., 1994). Iniciando-se o processo de deterioração logo após a semente atingir sua maturidade e estando esta relacionada com o processo de descoloração das sementes, ou seja, uma redução nos teores de clorofila no tegumento, a fluorescência de clorofila constitui-se num método não destrutivo que poderá vir a ser usado para prever o potencial de um lote de sementes.

\subsection{Teste de tetrazólio}

Na Tabela 5 encontram-se os resultados obtidos no teste de tetrazólio para as diferentes classes de fluorescência de clorofila, das umbelas primária, secundária e terciária. Observa-se uma relação entre as classes de fluorescência de clorofila, independentemente da umbela de origem, com a ocorrência de embriões normais, de embriões imaturos e de embriões mortos. Assim, foram observadas diferenças estatísticas significativas, para embriões normais, entre as classes de baixa, média e alta fluorescência de clorofila, dentro de cada umbela de origem. $\mathrm{Na}$ classe de baixa fluorescência de clorofila encontram-se valores médios de embriões normais de $84 \%$ para as umbelas primária e secundária e $80 \%$ para a umbela terciária. Resultados semelhantes foram obtidos por diversos autores que relataram que a qualidade das sementes de cenoura seria mais dependente do grau de maturidade do embrião do que propriamente da umbela de origem. 
Tabela 5. Estádio de desenvolvimento de embriões avaliado pelo teste de tetrazólio (\%), em sementes de cenoura oriundas de três umbelas, em três classes de fluorescência de clorofila, baixa (10-20 pA), média (20-40 pA) e alta (> 40 $\mathrm{pA})$.

\begin{tabular}{ccccc}
\hline Umbela & FC & Emb. Normal & Emb. Imaturo & Emb. Morto \\
\hline Primária & Baixa & $84 \mathrm{a}^{*}$ & $12 \mathrm{a}$ & $4 \mathrm{a}$ \\
& Média & $74 \mathrm{~b}$ & $20 \mathrm{a}$ & $6 \mathrm{a}$ \\
& Alta & $23 \mathrm{c}$ & $59 \mathrm{~b}$ & $18 \mathrm{~b}$ \\
\hline \multirow{2}{*}{ Secundária } & Baixa & $84 \mathrm{a}$ & $12 \mathrm{a}$ & $4 \mathrm{a}$ \\
& Média & $76 \mathrm{~b}$ & $18 \mathrm{a}$ & $6 \mathrm{a}$ \\
& Alta & $28 \mathrm{c}$ & $61 \mathrm{~b}$ & $11 \mathrm{~b}$ \\
& Baixa & $80 \mathrm{a}$ & $16 \mathrm{a}$ & $4 \mathrm{a}$ \\
Terciária & Média & $74 \mathrm{~b}$ & $20 \mathrm{a}$ & $6 \mathrm{a}$ \\
& Alta & $29 \mathrm{c}$ & $60 \mathrm{~b}$ & $11 \mathrm{~b}$ \\
\hline
\end{tabular}

*Médias seguidas por letras distintas, nas colunas, diferem pelo teste de Student ao nível de significância de 0,05 .

A influência do tamanho da semente e a presença de embriões normais, sobre a qualidade fisiológica de sementes de cenoura, foi estudada com o emprego do teste de tetrazólio por autores como Austin \& Longden (1967), Jacobsohn \& Globerson (1980) e Usik (1981), os quais observaram que as sementes de menor tamanho apresentavam embriões de tamanho menor, juntamente com aumento na ocorrência de embriões imaturos e mortos e, em conseqüência, menor percentagem de germinação, de emergência em campo e de rendimento em relação às sementes de maior tamanho. A mesma evidência foi verificada por Krarup \& Villanueva (1977) e Gray \& Steckel (1983a), em que as sementes maiores apresentaram maior peso e embriões normais maiores e, por conseguinte, produziam plântulas normais em maior percentual.

Na Figura 3 podemos observar um embrião normal, total e uniformemente colorido. Carvalho \& Nakagawa (1983), relataram que a ocorrência de embriões normais está diretamente relacionada com a maturidade das sementes. 


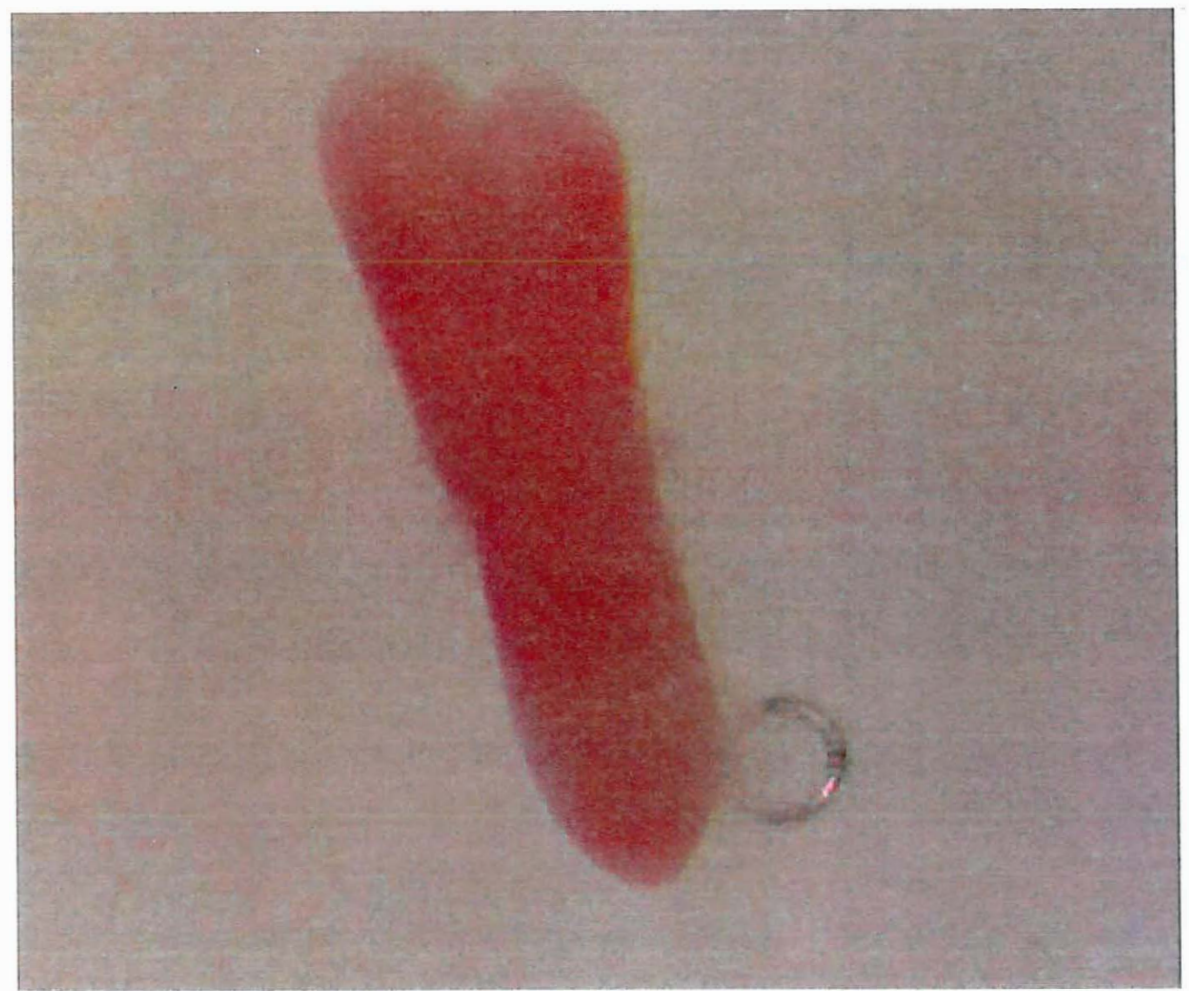

Figura 3 - Embrião normal de cenoura. 
Para a ocorrência de embriões imaturos e mortos, somente foi observada diferença estatística significativa entre as classes baixa e média em relação à classe alta, onde a ocorrência de embriões imaturos e mortos é maior para a fração de maior fluorescência de clorofila.

Andreoli \& Maguire (1987), por meio do teste de tetrazólio, detectaram sementes de cenoura sem embrião. As sementes remanescentes, que permaneceram intactas ao final do teste de germinação, foram embebidas numa solução de tetrazólio $(0,5 \%)$ a $32^{\circ} \mathrm{C}$ por 24 horas. Dissecadas longitudinalmente as sementes e examinadas em lupa estereoscópica (aumento de 60-80 vezes), verificaram que as sementes sem embrião apresentavam uma cavidade no endosperma. Não havendo alterações na forma da semente ou em seu peso, devido ao fato do peso do embrião ser ínfimo em comparação com o peso total da semente, relataram não ser possível eliminar as sementes sem embrião ou com embrião rudimentar no processo de beneficiamento.

Com o emprego do teste de tetrazólio é possível a identificação das sementes com maior qualidade fisiológica, no entanto é necessária a dissecação da semente para se observar as condições do embrião, tornando o processo lento, exaustivo e por vezes impreciso. Por ser um método destrutivo não permite efetuar a relação entre as características do embrião e o desempenho da sementes na germinação.

Nas Figuras 4 e 5 podemos observar, respectivamente, um embrião imaturo e um embrião morto; tal ocorrência tem sido relatada há muitos anos. Andrade et al. (1996), desenvolveram estudos onde, em média, 5,0\% das sementes não apresentavam embrião, $1,1 \%$ com embrião de tamanho rudimentar e $14,8 \%$ com embriões mortos e infectados. A ocorrência de sementes sem embrião e de embrião rudimentar foi atribuída, principalmente, à maturação desuniforme das diferentes umbelas. 


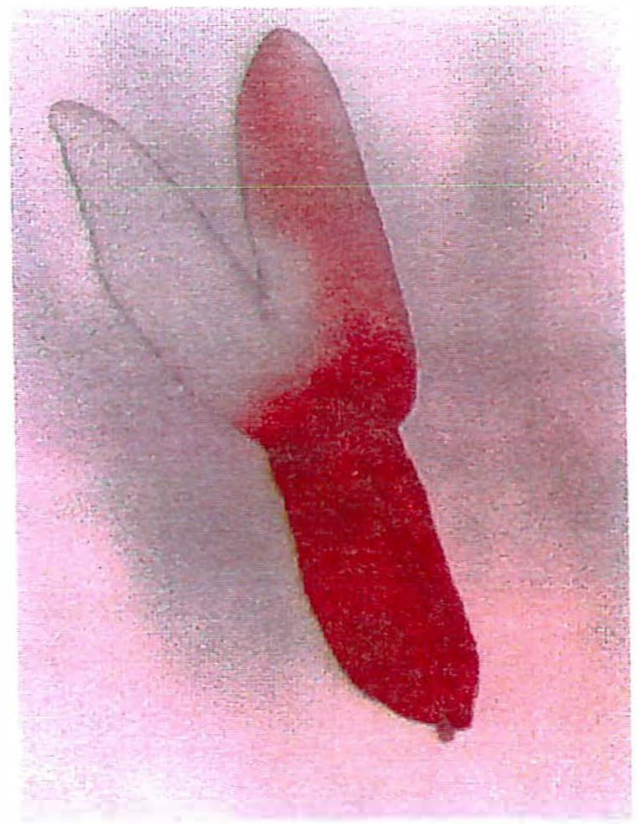

Figura 4 - Embrião imaturo de cenoura.

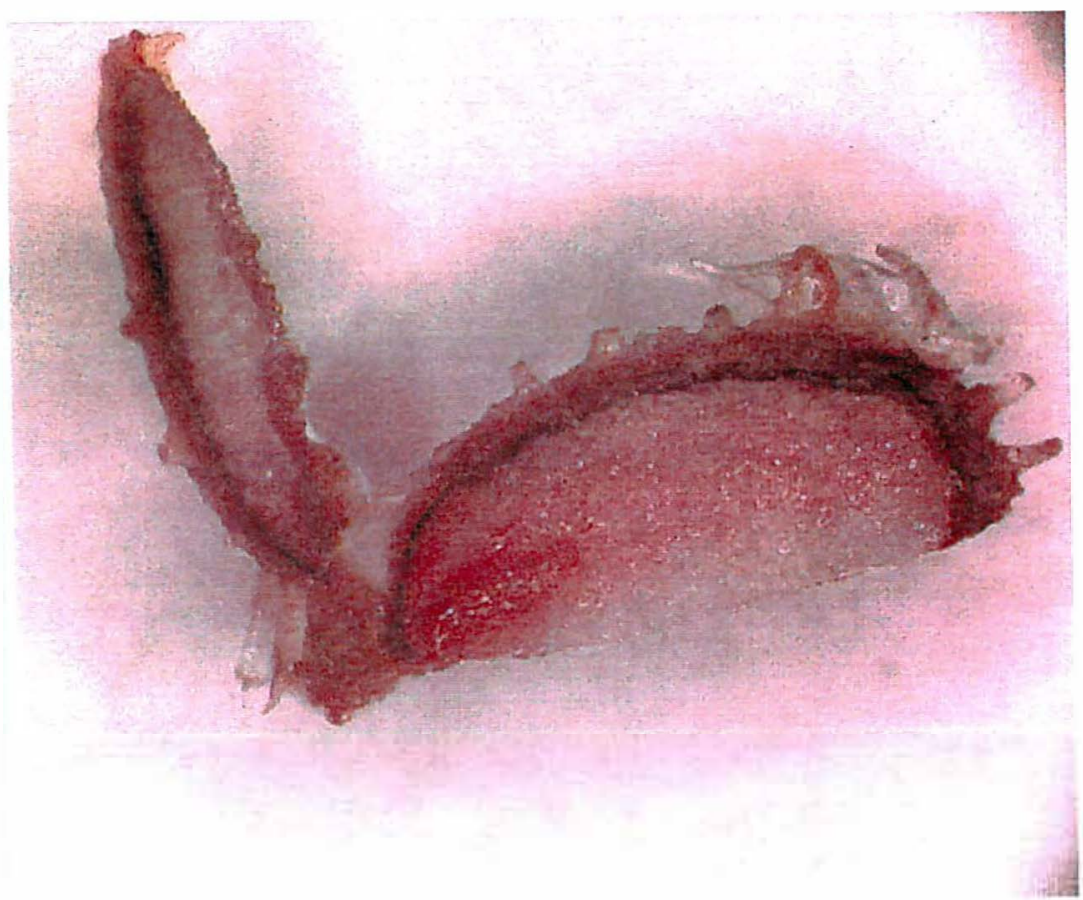

Figura 5 - Embrião morto de cenoura. 


\section{CONCLUSÕES}

Com base nos resultados obtidos conclui-se que o uso de fluorescência de clorofila de sementes de cenoura, como um método não destrutivo, é viável para determinar a qualidade fisiológica de sementes com diferentes níveis de maturidade. Pois, sementes com teor de fluorescência de clorofila entre 10-20 pA, independentemente da umbela de origem, apresentaram maiores valores de germinação e de vigor, em relação àquelas com teor de clorofila mais elevado (acima de 20 pA). 


\section{REFERÊNCIAS BIBLIOGRÁFICAS}

ANDRADE, R.N.B. Interação entre armazenamento e qualidade fisiológica de sementes de cenoura. Pelotas, 1993. 85 p. Dissertação (M.S.) - Universidade Federal de Pelotas.

ANDRADE, R.N.B.; SANTOS, D.S.B.; SANTOS FILHO, B.G.; MELLO, V.D.C. Testes de germinação de tetrazólio em sementes de cenoura armazenadas por diferentes períodos. Revista Brasileira de Sementes, v.18, n.1,p.108-116, 1996.

ANDRADE, R.N.B.; IWASAKI, K.; ANDRADE, A.P.; SANTOS, D.S.B.; SANTOS, B.G.; MELLO, V.D.C. Produtividade e qualidade fisiológica das sementes de cenoura cv. TAITC-Original, obtida através do método com e sem poda. Revista Brasileira de Sementes, v.15, n. 1, p.43-48, 1993.

ANDREOLI, C.; MAGUIRE,J.C. Viabilidade genética para germinação de sementes sem embrião em cenoura. Revista Brasileira de Sementes, v.3, p.57-6, 1987.

AUSTIN, R.B.; LONGDEN, P.C. Some effects of seed size and Maturity on the Yield of Carrot. Crops Journal of Horticultural Science, v.42, p.339-353, 1967.

BENJAMIN, L.R. Some effects of differing times of seedling emergence, population density and seed size on root-size variation in carrot populations. Journal of Agricultural Science, v.98, p.537-545, 1982.

BENJAMIN, L.R. A single equation to quantify the hierarchy in plant size induced by competition within monocultures. Annals of Botany, v.62, p.199-214, 1988.

BITTENCOURT, M.L.C. Qualidade das Sementes e Avaliação de Progênies de MeiosIrmãos de Cenoura (Daucus carota L.) 'Brasilia'. Viçosa, 1991. 77 p. Dissertação (M.S.) - Universidade Federal de Viçosa. 
BORTHWICK, H.A. Carrot seed germination. Procedings of the American Society for Horticultural Science, v.28, p.310-314, 1931.

BRASIL. Ministério da Agricultura e Reforma Agrária. Secretaria Nacional de Defesa Agropecuária. Regras para análise de sementes. Brasília, 1992. 365p.

CABRERA, E.R.; DIAZ, J. removal of ballonvine seed from soybeans using na eletronic colour sorting machine. Seed Science \& Technology, v.19, p.203-206, 1991.

CARVALHO, N.M.; NAKAGAWA, J. Sementes: ciência, tecnologia e produção. 3.ed. Campinas: Fundação Cargill, 1983. 424 p.

CASTRO, L.A.B.; ANDREWS, C.H. Fatores influenciando o rendimento e qualidade de sementes de cenoura (Daucus carota L.). Arquivos da Universidade Federal Rural do Rio de Janeiro, v.1, n.2, p.19-28, 1971.

COPELAND, L.; Mc DONALD, M.B. Principles of seed science and technology. Minneapolis: Burgess Publi., 1995. 409 p.

DE VOS, C.H.R.; KRAAK, H.L.; BINO, R.J. Ageing of tomato seeds involves glutathione oxidation. Physiologia Plantarum, v.92, p.131-139, 1994.

GRAY, D.; STECKEL, J.R.A. A comparison of methods for evaluating seed quality in carrots (Daucus carota L.). Annals of Applied Biology, v.103, p.327-334, 1983a. GRAY, D.; STECKEL, J.R.A. Seed quality in carrots: the effects of seed crop plant density, harvest date and seed grading on seed and seedling variability. Journal of Horticultural Science, v.58, n.3, p.393-401, 1983 b.

GRAY, D.; STECKEL, J.R.A. Some effects of umbel order and harvest date on carrot seed variability and seedling performance. Journal of Horticultural Science, v.58, n.1, p.73-82, $1983 \mathrm{c}$.

GRAY, D.; STECKEL, J.R.A.; JONES, S.R.; SENIOR, D. Correlation between variability in carrot (Daucus carota L.) plant weight and variability in embryo lenght. Journal of Horticultural Science, v.61, p.71-80, 1986. 
HAMPTON, J.G.; COOLBEAR, P. Potential versus actual seed performance, can vigour testing provide an answer. Seed Science \& Technology, v.18, p.215-228, 1990.

INTERNATIONAL SEED TESTING ASSOCIATION. International rules for seed testing. Seed Science \& Technology, v.24, p.437-465, 1996.

JACOBSOHN, R.; GLOBERSON, D. Daucus carota (carrot) seed quality: I. Effect of seed size on germination, emergence and plant growth under subtropical conditions and II. The importance of the primary umbel in carrot - seed production. Volcani Center, p.637-646, 1977./ Resumo 8027 em Horticultural Abstracts, v.50, n.11, p.665, 1980/

JALINK, H.; SCHOOR, R. van der. Seed Calculator ${ }^{\text {TM }}$ 2.1: windows version, user's guide. Wageningen: CPRO - DLO, 2000. 17p.

JALINK, H.; FRANDAS, A.; SCHOOR, R. van der; BINO, R.J. Chlorophyll fluorescence of the testa of Brassica oleracea seeds as na indicator of seed maturity and seed quality. Scientia Agricola, v.55, p.88-93, $1998 \mathrm{~b}$.

JALINK, H.; SCHOOR, R. van der; FRANDAS, A.; PIJLEN, J.G. van; BINO, R.J. Chorophyll fluorescence of Brassica oleracea seeds as a non-destructive marker of seed maturity and seed performance. Seed Science Research, v.8, p.437-443, 1998a.

JOHNSON-FLANAGAN, A.M.; THIAGARAJAH, M.R. Degreening in canola (Brassica napus cv. Wester) embryos under optimum conditions. Journal of Plant Physiology, v.136, p.180-186, 1990.

KEEFE, P.D.; DRAPER, S.R. The measurement of new characters for cultivar identification in wheat using machine vision. Seed Science \& Technology, v.14, p.715-724, 1986.

KRARUP, A.H.; VILLANUEVA, G. Producion de semilla de zanahoria VI - Relacion entre el tamaño del embrion y el percentage de germinacion de semillas provenientes de distintos ordenes florales. Agro Sur, v.5, n.1, p.45-48, 1977. 
KRARUP, A.H.; MONTEALEGREE, J.A.; MORETTI, J.S. Producion de semilla de zanahoria, III - Rendimento, contribuicion y gerninacion de semillas por ordenes florales. Agro Sur, v.4, n.2, p.81-87, 1976.

LIBERAL, O.H.T. Padrões de germinação em sementes de cenoura (Daucus carota L.). Revista Semente, v.1, n.2, p. 23-28, 1976.

MANN, L.K.; MACGILLVRAY, J.M. Some factors affecting the size of carrot roots. Procedings of the American Society for Horticultural Science, v.54, p.311-318, 1949.

Mc GREGOR, D.I. Influence of environment and genotype on rapeseed/canola seed chlorophyll content. Seed Science \& Technology, v.19, p.107-116, 1991.

MILLS, J.T.; WOODS, S.M.; WATTS, B.M.; LAMARI, L.; WHITE, N.D.G. Comparison of techniques to mesure seed color and its relantionship to other quality parameters in stored lentil (Lens culinaris Medik.). Seed Science \& Technology, v.27, p.1015-1021, 1999.

NASCIMENTO, W.M.; GUEDES, A.C. Efeito do método de colheita na produção de sementes de cenoura. Horticultura Brasileira, v.7, n.2, p.23-27, 1989.

NOBEL, P.S. Plant cell physiology: a physicochemical aproach. San Francisco: W.H. Freeman, 1970. 250 p.

POPINIGIS, F. Fisiologia de sementes. Brasilia: Ministério da Agricultura, AGIPLAN, 1985. $288 \mathrm{p}$.

REGHIN, M.Y.; BRAZ, L.T.; ODA, N. Influência da Semente Originária de Umbelas de Ordem Primária, Secundária e Terciária na Produção de Cenoura. Poliagro, v.8, n.2, p.79-82, 1986.

SALTER, P.J.; CURRAH, I.E.; FELLOWS, J.R. Studies on some sources of variation in carrot root weight. Journal of Agricultural Science, v.96, p.549-556, 1981.

SCHREIBER, U. Detection of rapid induction kinetics with a new type of high frequency modulated chlorophyll fluorometer. Photosynthesis Research, v.9, p.261-272, 1986. 
STECKEL, J.R.A.; GRAY, D.; ROWSE, H.R. Relationships between indices of seed maturity and carrot seed quality. Annals of Applied Biology, v.114, p.177-183, 1989.

TAYLOR, A.G.; MIN, T.G.; MALLADER, C.A. Seed coating system to upgrade brassicaceae seed quality by exploiting sinapine leakage. Seed Science \& Technology, v.19, p.423-433, 1991.

TAYLOR, A.G.; CHURCHILL, D.B.; LEE, S.S.; BILSLAND, D.M.; COOPER, T.M. Color sorting of coated brassica seeds by fluorescent sinapine leakage to improve germination. Journal of the American Society for Horticultural Science, v.118, p.551-556, 1993.

TKACHUK, R.; KUZINA, F.D. Chlorophyll analysis of whole rapeseed kernels by near infrared reflectance. Canadian Journal of Plant Science, v.62, p.875-884, 1982.

USIK, G.E. Effect of seed size on emergence and yield in onions and carrots. Intensifik, p. 30-33, 1980. / Resumo 1876 em Horticultural Abstracts, v.51, n.3, p.155-156, 1981/

VAN DE VOOREN, J.G.; VAN DER HEIJDEN, G.W.A.M. Measuring the size of french beans with image analysis. Plant Varieties and Seeds, v.6, p.47-53, 1993.

VERTUCCI, C.W.; ELLENSON, J.L.; LEOPOLD, A.C. Chlorophyll fluorescence characteristics associated with hydration level in pea cotyledons. Plant Physiology, v.79, p.248-252, 1985.

WARD, K. The effect of genotype, environment and agronomic practices on the chorophyll level in harvested canola seed. Winnipeg, 1990. 127 p. Thesis (PhD) University of Manitoba.

WARD, K.; SCARTH, R.; DAUN, J.K.; Mc VETTY, P.P.E. Effects of genotype and environment on seed chorophyll degradation during ripening in four cultivars of oilseed rape (Brassica napus). Canadian Journal of Plant Science, v.72, p.643649, 1992. 
WARD, K.; SCARTH, R.; DAUN, J.K.; VESSEY, J.K. Chorophyll degradation in summer oilseed rape and summer turnip rape during seed ripening. Canadian Journal of Plant Science, v.75, p.413-420, 1995.

WERKER, E. Seed anatomy. Berlin: Gebrüden Bornträger, 1997. 275 p.

ZAYAS, I.; POMERANZ, Y.; LAI, F.S. Discrimination of wheat and nonwheat components in grain samples by image analysis. Cereal Chemistry, v.66, n.3, p.233-237, 1989. 